\title{
Circulating maternal cortisol levels during vaginal delivery and elective cesarean section
}

\author{
Ylva Vladic Stjernholm ${ }^{1} \cdot$ Annie Nyberg $^{2} \cdot$ Monica Cardell $^{3} \cdot$ Charlotte Höybye $^{4}$
}

Received: 27 August 2015/Accepted: 1 December 2015/Published online: 21 December 2015

(C) The Author(s) 2015. This article is published with open access at Springerlink.com

\begin{abstract}
Introduction Maternal S-cortisol levels increase throughout pregnancy and peak in the third trimester. Even higher levels are seen during the physical stress of delivery. Since analgesia for women in labor has improved, it is possible that maternal stress during labor is reduced. The aim of this study was to compare maternal S-cortisol during vaginal delivery and elective cesarean section.

Materials and methods Twenty healthy women with spontaneous vaginal delivery and healthy women $(n=20)$ undergoing elective cesarean section were included in the study. S-cortisol was measured during three stages of spontaneous vaginal delivery (tvd1, tvd2 and tvd3), as well as before and after elective cesarean section (tcs 1 and tcs2). Results In the vaginal delivery group, mean S-cortisol at tvd1 was $1325 \pm 521 \mathrm{nmol} / \mathrm{L}$, at tvd2 $1559 \pm 591 \mathrm{nmol} / \mathrm{L}$ and at tvd3 $1368 \pm 479 \mathrm{nmol} / \mathrm{L}$. In the cesarean section group, mean S-cortisol at tcs 1 was $906 \pm 243 \mathrm{nmol} / \mathrm{L}$ and at tcs2 $831 \pm 257 \mathrm{nmol} / \mathrm{L}$. S-cortisol was higher in the vaginal delivery group at the onset of labor as compared to the cesarean section preoperative group $(p=0.006)$. There
\end{abstract}

Ylva Vladic Stjernholm

ylva.vladic-stjernholm@karolinska.se

1 Department of Women's and Children's Health, Karolinska Institute and Karolinska University Hospital,

17176 Stockholm, Sweden

2 Medical School, Karolinska Institute, Stockholm, Sweden

3 Department of Women's and Children's Health, Skåne University Hospital, Lund, Sweden

4 Department of Endocrinology, Metabolism and Diabetology, Karolinska Institute and Karolinska University Hospital, Stockholm, Sweden were also significant differences between S-cortisol levels postpartum as compared to postoperatively $(p<0.001)$. Conclusions Maternal S-cortisol was higher during vaginal delivery compared to elective cesarean section, indicating higher stress levels. A reduction in the hydrocortisone dose at childbirth in women with adrenal insufficiency should be considered, particularly in women undergoing an elective cesarean section.

Keywords Cesarean section $\cdot$ Cortisol $\cdot$ Delivery $\cdot$ Stress

$\begin{array}{ll}\text { Abbreviations } \\ \text { AI } & \text { Adrenal insufficiency } \\ \text { ACTH } & \text { Adrenocorticotropic hormone } \\ \text { CS } & \text { Cesarean section } \\ \text { CBG } & \text { Corticosteroid-binding globulin } \\ \text { CRH } & \text { Corticotropin-releasing hormone } \\ \text { EDA } & \text { Epidural analgesia } \\ \text { SPA } & \text { Spinal analgesia } \\ \text { VD } & \text { Vaginal delivery }\end{array}$

\section{Introduction}

In the pregnant woman, circulating levels of cortisol, corticosteroid-binding globulin (CBG), corticotropin-releasing hormone (CRH) and adrenocorticotropic hormone (ACTH) are increased compared to the non-pregnant state, resulting in an altered sensitivity of the HPA axis, creating physiological hypercortisolism [1]. The placenta is believed to play an important role by secreting $\mathrm{CRH}$ and ACTH, leading to increased levels of cortisol, and unlike hypothalamic $\mathrm{CRH}$, placental $\mathrm{CRH}$ is not regulated by 
negative feedback [2-5]. Instead, rising fetal cortisol stimulates further release of CRH from the placenta [6]. $\mathrm{CRH}$ levels increase during pregnancy with the highest levels seen in the third trimester. Levels subsequently decrease to non-pregnant levels within a few hours after childbirth [6-8]. ACTH reaches its highest level during labor and rapidly decreases toward non-pregnant values after delivery [9]. In addition to the elevated levels of CRH and $\mathrm{ACTH}$, other mechanisms contribute to the rise in circulating cortisol. Elevated estrogen levels stimulate the liver production of CBG such that less free cortisol is available for negative feedback, which leads to an enhanced cortisol synthesis [2]. Furthermore, the clearance of cortisol is decreased [3].

Labor is assumed to be a physiologically stressful situation. However, reports on maternal S-cortisol levels during delivery are scarce and only a few studies have been published $[3,8,10,11]$. In a study from 1976, Goldkrand et al. [10] showed that vaginal delivery (VD) was associated with higher circulating cortisol compared to cesarean section (CS). In 1987, Kono et al. [11] found that maternal cortisol levels correlated with parity and duration of labor.

Adrenal insufficiency (AI) during pregnancy is either primary or secondary, with exogenous corticosteroid therapy as by far the most common etiology. Women with AI are monitored closely during pregnancy and receive increased doses of hydrocortisone during pregnancy and delivery. In women who are treated with steroids, the dose is minimized during pregnancy. In connection with labor and cesarean section, most guidelines recommend standardized supplemental doses of hydrocortisone irrespective of the patients daily prescribed dose. However, symptoms of hypercortisolism such as hypertension, anxiety, restlessness and insomnia after such increases in the cortisone substitution are, in our experience common, indicating that we might be overcompensating the supposed deficit.

Since AI during pregnancy is rare, the present study was designed to quantify maternal S-cortisol in healthy women during spontaneous VD and elective CS. Data were then interpreted in the context of hydrocortisone cortisone replacement therapy with special regard to present-day recommendations.

\section{Materials and methods}

This pilot study was approved by the Ethical Board for Medical Sciences in Stockholm, Sweden, DNr 2013/17831/4. Between September 1, 2014, and February 28, 2015, 1,889 deliveries and 178 elective CS were registered at the Department of Women's and Children's Health, Karolinska University Hospital, Solna, Sweden. Women who were eligible for the study were included after oral and written consent. Maternal S-cortisol levels were measured during spontaneous VD and at elective CS.

\section{Study participants}

Inclusion criteria were healthy women with uncomplicated pregnancies. Exclusion criteria were multiple pregnancy, concomitant diseases such as diabetes mellitus or pituitary disease, ongoing steroid therapy, and pregnancy complications such as preeclampsia or gestational diabetes. The VD group included women $(n=20)$ with spontaneous VD at term gestational age. Peripheral venous samples were obtained at three stages of labor: (tvd1) during the first stage of labor at a cervical dilatation of $4-6 \mathrm{~cm},(\operatorname{tvd} 2)$ during the second stage of labor when the uterine cervix was fully dilated and (tvd3) during the third stage, i.e., within $2 \mathrm{~h}$ after delivery of the placenta. The cervical diameter was continuously assessed by a midwife. The CS group included women $(n=20)$ undergoing elective CS before onset of labor. The most common indication for a planned CS was two previous CS or fear of childbirth. Peripheral venous samples were obtained before and after elective CS: preoperatively (tcs1) and within $2 \mathrm{~h}$ postoperatively (tcs2).

Analyses of S-cortisol were performed at the Department of Clinical Chemistry, Karolinska University Hospital, using electrochemical luminescence, Modular E, Roche Diagnostics, Mannheim, Germany.

Clinical data regarding maternal age, body mass index (BMI), parity, gestational age, duration of labor, indications for and duration of CS, type of analgesia such as epidural analgesia (EDA), spinal analgesia (SPA), inhalation of nitrous oxide $\left(\mathrm{N}_{2} \mathrm{O}\right)$ in combination with oxygen or other medication were obtained from computerized medical records.

\section{Statistics}

Data were presented as mean and standard deviation (SD). For comparison between groups, Student's $t$ test was used for normally distributed data and Mann-Whitney $U$ test for non-normally distributed data. $p$ values of $<0.05$ were considered significant.

\section{Results}

Clinical data are shown in Table 1. The maternal age and proportion of primiparity did not differ, whereas the mothers in the CS group had a higher BMI $(p=0.005)$. The duration of VD ranged between 185 and $1075 \mathrm{~min}$, mean $624 \mathrm{~min}$. The average duration in primiparous women $(n=13)$ was $728 \mathrm{~min}$ and in parous women with 
Table 1 Clinical data

\begin{tabular}{llll}
\hline Variable & VD $(n=20)$ & CS $(n=20)$ & $p$ value \\
\hline Maternal age (years) (median and range) & $33(23-42)$ & $33(24-43)$ & $>0.05$ \\
BMI $\left(\mathrm{kg} / \mathrm{m}^{2}\right)$ (median and range) & $23(18-28)$ & $26(21-34)$ & $>0.05$ \\
Primiparous (\%) & $13(65)$ & $7(35)$ & $>0.05$ \\
Gestational age (weeks) (median and range) & $40(38-41)$ & $39(37-39)$ & $>0.05$ \\
Regional anesthesia (\%) & $15(75)$ & $20(100)$ & $>0.05$ \\
Birth weight $(\mathrm{g})$ (mean $\pm \mathrm{SD})$ & $3617 \pm 457$ & $3492 \pm 452$ & $>0.05$ \\
Apgar score $<7$ at 5 min & 0 & 0 & $>0.05$ \\
\hline
\end{tabular}

Table 2 Maternal S-cortisol $(\mathrm{nmol} / \mathrm{L}$, mean $\pm \mathrm{SD})$

\begin{tabular}{|c|c|c|c|c|c|}
\hline & tvd 1 & $\operatorname{tvd} 2$ & $\operatorname{tvd} 3$ & $\operatorname{tcs} 1$ & $\operatorname{tcs} 2$ \\
\hline VD & $1325 \pm 521 *$ & $1559 \pm 591$ & $1368 \pm 479^{* *}$ & & \\
\hline $\mathrm{CS}$ & & & & $906 \pm 243 *$ & $831 \pm 257 * *$ \\
\hline
\end{tabular}

Sample tvd1 during the first stage of labor, tvd2 during the second stage and tvd 3 during the third stage. Sample tcs 1 before elective CS, tcs 2 within $2 \mathrm{~h}$, postoperatively

$* p=0.06 ; * * p<0.001$ one previous vaginal delivery $(n=6) 394 \mathrm{~min}$. One parous woman with a medical history of one previous VD and one CS had a delivery lasting $661 \mathrm{~min}$. The duration of the elective CS ranged between 17 and 60 min with an average of $37 \mathrm{~min}$.

Maternal S-cortisol levels are shown in Table 2, Figs. 1 and 2. In the VD group, mean S-cortisol at tvd1 was $1325 \pm 521 \mathrm{nmol} / \mathrm{L}$, at tvd $21559 \pm 591 \mathrm{nmol} / \mathrm{L}$ and at tvd3 $1368 \pm 479 \mathrm{nmol} / \mathrm{L}$ (Fig. 1). There were no significant differences between the three measurements. There was no correlation between S-cortisol at tvd1, tvd2 or tvd3 and maternal age, BMI, parity, gestational age or duration of labor (data not shown). The highest S-cortisol level was $2710 \mathrm{nmol} / \mathrm{L}$, observed during the second stage of labor (tvd2). A peak S-cortisol was observed at tvd1 in 6 women

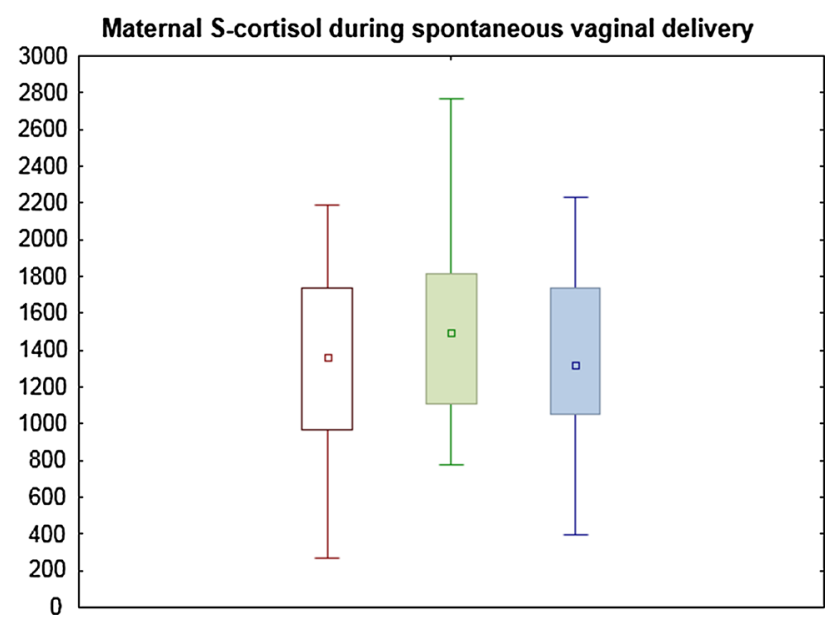

Fig. 1 Maternal S-cortisol during spontaneous vaginal delivery
$(30 \%)$, at tvd2 in 10 women $(50 \%)$ and at tvd3 in 4 women $(20 \%)$. The largest increment was $44 \%$, from $1200 \mathrm{nmol} / \mathrm{L}$ at tvd1 to $2710 \mathrm{nmol} / \mathrm{L}$ at tvd2. Notably, S-cortisol was decreased during the second stage of labor in six women.

In the CS group, mean S-cortisol was $906 \pm 243 \mathrm{nmol} /$ $\mathrm{L}$ at $\operatorname{tcs} 1$ and $831 \pm 257 \mathrm{nmol} / \mathrm{L}$ at tcs 2 (Fig. 2). There were no significant differences between these measurements $(p=0.352)$. There was no correlation between S-cortisol at tcs1 or tcs2 and maternal age, BMI, parity, gestational age or duration of surgery (data not shown). A peak S-cortisol level was observed at tcs 1 in $60 \%$ and at tcs 2 in $40 \%$. The highest value was $1390 \mathrm{nmol} / \mathrm{L}$, observed postoperatively (tvd2). The difference between maternal S-cortisol at tvd1 in the VD group and tcs1 in the

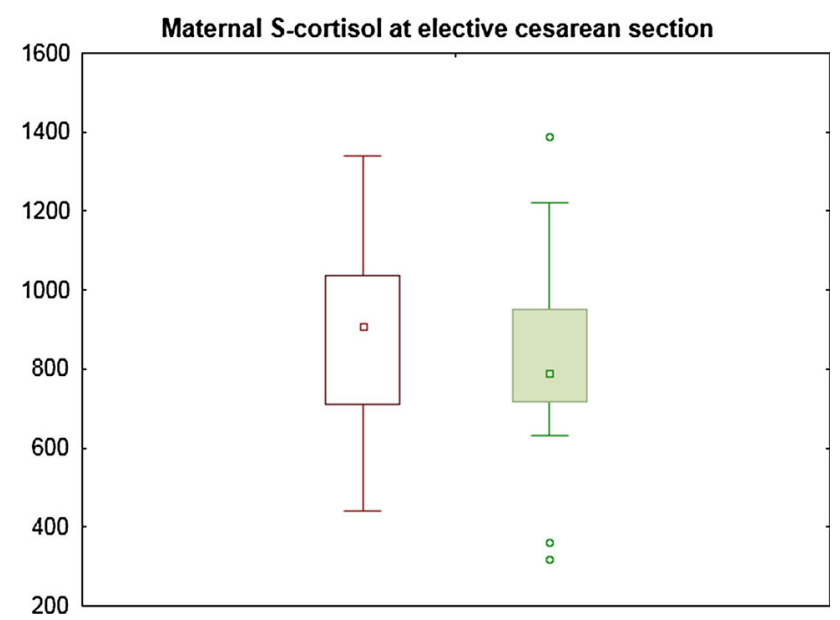

Fig. 2 Maternal S-cortisol at elective cesarean section 
CS group was significant $(p=0.006)$ as well as the difference between tvd 3 in the VD group and tcs 2 in the CS group $(p<0.001)$.

All women undergoing VD were offered labor analgesia including acupuncture, inhalation of $\mathrm{N}_{2} \mathrm{O} 50 \%$ in combination with oxygen $50 \%$ and epidural anesthesia (EDA). Fifteen women $(75 \%)$ in the VD group received EDA. Five women received only acupuncture and/or $\mathrm{N}_{2} \mathrm{O}$ with oxygen. According to the medical records, 13 women $(65 \%)$ in the VD group received EDA during the first stage of labor. There was no correlation between S-cortisol and different modes of analgesia (data not shown). Two women were delivered by ventouse due to a prolonged second stage of labor. In these women, S-cortisol levels were comparable to the levels during unassisted delivery. In the elective CS group, all women received spinal anesthesia (SPA) before surgery.

\section{Discussion}

In this study, we monitored serial maternal S-cortisol in healthy women with uncomplicated pregnancies throughout the different stages of VD, as compared to elective CS before the onset of labor. S-cortisol during VD was comparable to the values reported in previous studies, whereas the levels at elective CS were lower than was reported previously. However, only single measurements were taken in earlier studies. We found that spontaneous VD generated higher maternal S-cortisol than elective CS, indicating higher stress levels. We found no correlation between S-cortisol and maternal age, BMI, parity, gestational age or duration of labor.

A two- to fourfold increase in S-cortisol from $336 \pm 16 \mathrm{nmol} / \mathrm{L}$ at 16 gestational weeks $(n=33)$ to $810 \pm 82 \mathrm{nmol} / \mathrm{L}$ at 38 gestational weeks $(n=31)$ has been reported [12]. A variation in S-cortisol between 450 and $1518 \mathrm{nmol} / \mathrm{L}$ in the third trimester in normal pregnancies has been described [13]. The S-cortisol levels before elective CS in the present study tcs 1 were comparable to the third trimester levels, as reported by Ho et al. [12]. There are no previous reports on S-cortisol levels at emergency CS. However, S-cortisol levels during emergency CS performed before active labor would be similar to the levels observed during the first stage in the VD group (tvd1). Likewise, S-cortisol levels at emergency CS carried out during the active labor would be similar to the values observed during the second stage of labor in the VD group (tvd2).

In 1976, Goldkrand et al. [10] showed that maternal S-cortisol levels in 95 women were higher after VD as compared to after CS. They found that S-cortisol measured immediately after uncomplicated VD averaged at $52.2 \mu \mathrm{g} /$
$100 \mathrm{~mL}(1440 \mathrm{nmol} / \mathrm{L})$. In the CS group, mean S-cortisol values were $48.3 \mu \mathrm{g} / 100 \mathrm{~mL}(1333 \mathrm{nmol} / \mathrm{L})$. In 1987 , Kono et al. showed that maternal S-cortisol levels in 130 women during VD were higher in primiparous women $(64.3 \mu \mathrm{g} / 100 \mathrm{~L}(=1774.0 \mathrm{nmol} / \mathrm{L})$ than in parous women $(37.8 \mu \mathrm{g} / 100 \mathrm{~mL}(=1042.9 \mathrm{nmol} / \mathrm{L})[11]$. We did not find such a correlation, which might be due to the smaller sample size in our study. We hypothesized that the introduction of labor analgesia during the last decades might result in a reduction in maternal stress during delivery [14]. If so, lower S-cortisol levels at VD would be expected in today's clinical practice. S-cortisol values in the VD group were, however, comparable to the levels reported in previous studies. S-cortisol levels in the CS group were lower at tcs 1 and tcs 2 as compared to the VD group and compared to previous studies. These findings indicate that VD is more stressful than elective CS.

According to international guidelines, women with $\mathrm{AI}$ at the Karolinska University Hospital receive hydrocortisone 100-300 mg throughout labor and $24 \mathrm{~h}$ after delivery [2, 15]. After delivery, there is a reduction in the prepregnancy treatment dose over $48 \mathrm{~h}[2,15-18]$. The indications for $\mathrm{CS}$ in women with $\mathrm{AI}$ are similar to those in healthy women [2, 15-18]. Björnsdottir et al. [19] reported an increased risk of premature delivery and a higher frequency of CS in women with Addison's disease.

The reports on S-cortisol following intravenous (i v) injection of hydrocortisone are limited. In a study conducted in men, S-cortisol measured $10 \mathrm{~min}$ after an i v injection of hydrocortisone, $20 \mathrm{mg}$, was $1059 \mathrm{ng} / \mathrm{mL}$ (2921.7 nmol/L), whereas S-cortisol was $1854 \mathrm{ng} / \mathrm{mL}$ $(5115 \mathrm{nmol} / \mathrm{L})$ after an i v injection of $40 \mathrm{mg}$ hydrocortisone [20]. Our results, in combination with previous reports and taking into account complaints regarding symptoms of hypercortisolism, suggest that the recommended hydrocortisone doses at childbirth for women with AI may be too high. Therefore, a reduction in the hydrocortisone dose at childbirth in women with AI should be considered, particularly in the case of an elective CS. However, the optimal hydrocortisone dose has yet to be decided and should be adjusted to individual requirements. In this study, S-cortisol levels were not quantified during term pregnancy or during emergency CS. However, the S-cortisol levels observed before elective CS are comparable to the levels observed during term pregnancy, as shown by Ho et al. [12].

The strengths of this study were the consecutive S-cortisol monitoring during VD and at elective CS. To our knowledge, this is the first report on consecutive sampling of maternal S-cortisol. Due to practical reasons, samples were obtained at relatively long intervals. A more frequent sampling regime would probably not have changed the results significantly. 
The small sample size was a limitation. Therefore, correlations might have been detected between S-cortisol and different types of analgesia, maternal age, BMI, parity or duration of labor in a larger cohort. As in previous studies, total S-cortisol was measured and individual differences in the ratio between free (active) and CBG-bound cortisol were not determined. Saliva cortisol sampling may be a way to deal with this issue [20]. A quantification of S-cortisol after an i v injection, or after oral administration of a double dose of hydrocortisone in women with cortisol insufficiency, would be valuable in deciding on an optimal dose regime in connection with childbirth.

In conclusion, S-cortisol levels were significantly higher in women who underwent spontaneous VD compared to elective CS before the onset of labor, indicating that VD is more stressful than an elective CS. A reduction in the hydrocortisone dose administered at childbirth in women with AI should be considered, particularly in the case of elective CS. Larger studies exploring the S-cortisol levels in women with different parity, as well as in women undergoing emergency CS after the onset of labor might be helpful in establishing more precise guidelines for hydrocortisone treatment at childbirth in women with AI.

Author contributions Circulating maternal cortisol levels during vaginal delivery and elective cesarean section. Charlotte Höybye, Annie Nyberg and Ylva Vladic Stjernholm involved in study design. Annie Nyberg and Ylva Vladic Stjernholm involved in collection of data. Charlotte Höybye and Ylva Vladic Stjernholm involved in statistical calculations. Annie Nyberg, Charlotte Höybye, Monica Cardell and Ylva Vladic Stjernholm interpreted the data. Annie Nyberg, Charlotte Höybye, Monica Cardell and Ylva Vladic Stjernholm wrote the manuscript.

\section{Compliance with ethical standards}

Conflict of interest The authors declare that they have no conflict of interest.

Open Access This article is distributed under the terms of the Creative Commons Attribution 4.0 International License (http://crea tivecommons.org/licenses/by/4.0/), which permits unrestricted use, distribution, and reproduction in any medium, provided you give appropriate credit to the original author(s) and the source, provide a link to the Creative Commons license, and indicate if changes were made.

\section{References}

1. Jung C, Ho JT, Torpy DJ et al (2011) A longitudinal study of plasma and urinary cortisol in pregnancy and postpartum. J Clin Endocrinol Metab 96(5):1533-1540
2. Lindsay JR, Nieman LK (2005) The hypothalamic-pituitaryadrenal axis in pregnancy: challenges in disease detection and treatment. Endocr Rev 26(6):775-799

3. Mastorakos G, Ilias I (2003) Maternal and fetal hypothalamicpituitary-adrenal axes during pregnancy and postpartum. Ann N Y Acad Sci 997:136-149

4. Okamoto E, Takagi T, Makino T et al (1989) Immunoreactive corticotropin-releasing hormone, adrenocorticotropin and cortisol in human plasma during pregnancy and delivery and postpartum. Horm Metab Res 21(10):566-572

5. Robinson BG, Emanuel RL, Frim DM et al (1998) Glucocorticoid stimulates expression of corticotropin-releasing hormone gene in human placenta. Proc Natl Acad Sci USA 85(14):5244-5248

6. Scott EM, McGarrigle HH, Lachelin GC (1990) The increase in plasma and saliva cortisol levels in pregnancy is not due to the increase in corticosteroid-binding globulin levels. J Clin Endocrinol Metab 71(3):639-644

7. Campbell EA, Linton EA, Wolfe CD et al (1987) Plasma corticotropin-releasing hormone concentrations during pregnancy and parturition. J Clin Endocrinol Metab 64:1054-1059

8. Hillhouse EW, Grammatopoulos DK (2002) Role of stress peptides during human pregnancy and labour. Reproduction 124(3):323-329

9. Carr BR, Simpson ER (1981) Synthesis of cholesterol in the human fetus: 3-hydroxy-3-methylglutaryl coenzyme A reductase activity of liver microsomes. J Clin Endocrinol Metab 53:810-812

10. Goldkrand JW, Schulte RL, Messer RH (1976) Maternal and fetal plasma cortisol levels at parturition. Obstet Gynecol 47(1):41-45

11. Kono H, Furuhashi N, Shinkawa O et al (1987) The maternal serum cortisol levels after onset of labor. Tohoku J Exp Med 152:133-137

12. Ho JT, Lewis JG, O'Loughlin P et al (2007) Reduced maternal corticosteroid-binding globulin and cortisol levels in preeclampsia and gamete recipient pregnancies. Clin Endocrinol 66:869-877

13. Mukherjee K, Swyer GI (1972) Plasma cortisol and adrenocorticotrophic hormone in normal men and non-pregnant women, normal pregnant women and women with pre-eclampsia. J Obstet Gynaecol Br Commonw 79:504-512

14. Anim-Somuah M, Smyth RMD, Jones L (2011) Epidural versus non-epidural or no anal gesia in labour. Cochrane Database Syst Rev (12):CD000331. doi:10.1002/14651858.CD000331.pub3

15. Ambrosi B, Barbetta L, Morricone L (2003) Diagnosis and management of Addison's disease during pregnancy. J Endocrinol Invest 26(7):698-702

16. Albert E, Dalaker K, Jorde R et al (1989) Addison's disease and pregnancy. Acta Obstet Gynecol Scand 68(2):185-187

17. Lebbe M, Arlt W (2013) What is the best diagnostic and therapeutic management strategy for an Addison patient during pregnancy? Clin Endocrinol 78(4):497-502

18. van der Spuy ZM, Jacobs HS (1984) Management of endocrine disorders in pregnancy. II. Pituitary, ovarian and adrenal disease. Postgrad Med J 60:312-320

19. Björnsdottir S, Cnattingius S, Brandt L et al (2010) Addison's disease in women is a risk factor for an adverse pregnancy outcome. J Clin Endocrinol Metab 95(12):5249-5257

20. Laudat MH, Cerdas S, Fournier C et al (1988) Salivary cortisol measurement: A practical approach to assess pituitary-adrenal function. J Clin Endocrinol Metab 66:343-348 